\title{
Acem Ali Kimdir? Osmanlı Dönemi Hassa Baş Mimarı Alaeddin Ali b. Abdullah'ın Kişiliği ve Mesleki Kimliği Ü̉zerine Bir İnceleme
}

\author{
Hüseyin Gürsel BİLMiș ${ }^{1}$
}

\section{$\ddot{O} z$}

Osmanlı Devletinin imparatorluğa dönüştüğü yıllarda Acem Ali ve Mimar Sinan dönemin iki büyük mimarı, Ayas Paşa ve Lütfi Paşa ise iki siyaset adamıdır. Mimar Sinan'dan önceki mimarbaşı olan Acem Ali hakkında ilgili literatürde birbirinden oldukça farklı bilgiler bulunmaktadır. Yaygın iki görüşe göre Acem Ali ya Tebriz'den getirilen esir bir mimardır ya da, II. Bayezid döneminde Amasya'da mimarlık yapan, daha sonra İstanbul'a getirilen mimarlardan biridir. Yine, Acem Ali'nin ölüm tarihi ile Mimar Sinan'ın mimarbaşı olduğu tarih konusunda da kaynaklarda bir uzlaşının olmadığı görülmektedir. Bu makalede, Acem Ali'nin yaşamı ve mimarlı̆̆ına ilişkin farklı tespitler incelenerek, dökümleri yapılan iki vakfiye ile Rıfkı Melül Meriç’in arşiv belgelerine dayalı verileri üzerinden konuya açılık getirilmeye çalışılmıştır. Vakfiyeler ve Arşiv belgeleri esas alındığında mühtedi olduğu anlaşılan Acem Ali’nin Osmanlı hizmetindeki 36 yıllık mimarlık kariyerinin (1503-1539) büyük bir kısmını mimarbașı olarak vefatına kadar sürdürdügü, lakabına istinaden Acem Ali’nin “Tebriz'den getirilen İranlı bir mimar olduğu” şeklinde literatürde sıkça tekrarlanan bilginin ciddi bir kanıta dayanmadığı, Yavuz’un Tebriz seferinin çok öncesinde Amasya'ya gelmiş olmasının daha güçlü bir ihtimal olduğu sonucuna varılmıştır.

Anabtar Kelimeler: Acem Ali, Mimarbaşı, Mimarbaşı Sinan, Mimarlık Tarihi, Vakfiye

Who is Ajam Ali? A Study on the Personal and Professional Identity of Alaaddin Ali ibn Abdullah, the Chief Architect in the Period of Ottoman Empire

\begin{abstract}
In the years when the Ottoman State became Empire, Ajam Ali ['Ajam 'Ali] and Mimar Sinan were the two great architects, and Ayas Pasha and Lütfi Pasha were two politicians of the then. There are various contradictory information in the related contemporary literature concerning Ajam Ali who was the chief architect before Mimar Sinan. According to the common two views, Ajam Ali is a formerly captive architect brought from Tabriz, or He is one of the resident architects who worked in Amasya during the period of Bayezid II and later brought to Istanbul. There is also no consensus on the date of death of Ajam Ali and the date of which Mimar Sinan became the chief architect. In this article, we examined different views on Ajam Ali's life and his career as an architect in the related literature, and based on the data provided by Rifk1 Melul Meric through archival documents about Ajam Ali and his two waqfiyas, we tried to clarify the issue. We concluded that Ajam Ali, a Muslim convert as stated in waqfiyas and archival documents, continued the vast majority of his 36-year career in architecture (1503-1539) in the Ottoman Empire as a chief architect until his death, that there is no solid evidence on the claim that "he is an Iranian architect brought from Tabriz" inspired by his nickname "Acem", and that he may most probably have arrived in Amasya long before Tabriz Campaign of Selim I.
\end{abstract}

Key Words: Ajam Ali, Chief Architect, Chief Architect Sinan, Architecture History, Waqfiya

Atıf İçin / Please Cite As:

Bilmiş, H. G. (2020). Acem Ali kimdir? Osmanlı dönemi hassa baş mimarı Alaeddin Ali b. Abdullah'ın kişiliği ve mesleki kimliği üzerine bir inceleme. Manas Sosyal Araştırmalar Dergisi, 9(2), 1089-1100.

Geliş Tarihi / Received Date: 20.03.2019

Kabul Tarihi / Accepted Date: 03.06.2019 


\section{Giriş}

Acem Alisi ya da Acem Ali olarak bilinen ve Mimar Sinan'dan (öl.1588) önce Hassa mimarbaşı görevindeyken vefat eden Alaüddin Ali bin Abdullah'ın (öl.1539) bilinen iki vakfiyesi Acem Ali ile ilgili pek çok noktayı aydınlatmış, Rıfkı Melül Meriç'in Arşiv belgelerine dayalı görev-çalışma-ödüllendirme dökümleri de onun mimari yaşamını ortaya koymuştur. Ancak günümüze kadar Acem Ali ile ilgili yapılan farklı yayınlara bakıldığında bu meselenin kafa karıştırıcı bir halde olduğu görülür. Bu yazıda bahsedilen bilgi karmaşasına 1930 ’lu yıllardan sonra çelişkili tespitlerle ortaya konulan veriler neden olmaktadır. Bu verilerden hareketle üretilen çalışmalar ise, mevcut konunun gereği gibi aydınlatılamadan, eski bilgiler üzerinde devam/tekrar ettirilerek, o alanda bir literatür sorunu oluşturulmasina meydan vermektedir. Acem Ali Tebriz'den getirilen esir bir mimar midır, ya da Amasya'da II. Bayezid'in yerel mimarlarından mıdır? Saray'da yetişip mimarbaşı olmuş mudur? Sinan ne zaman mimarbaşı olmuştur? Ölümü $1537 \mathrm{mi}$ 1539 mudur? Bu gibi sorular ve bunlara dayalı çelişkili tespitler, konu hakkında bir karmaşaya sebep olmaktadır, çünkü hemen herkesin kendi bakış açısına göre farklı bir Acem Ali’si vardır. Kısacası literatürde adı geçen Acem Ali kimdir? Bu çalışmada, Acem Ali ile ilgili birbiriyle çelişkili tespitlerin oluşturduğu bilgilere atıfla, vakfiye ve arşiv belgeleri üzerinden mevcut karışıklık giderilmeye çalışılmıştır. Belgelerin verilerine uygun, gerçekçi ve konuyu netleştirecek daha makul yorumlara atıf yapılmıştır. $\mathrm{Bu}$ yöntemle karmaşaya sebep olan noktaların az da olsa açılığa kavuşturulması amaçlanmıştır.

\section{Gerçeklik İle Karmaşa Arasında Acem Ali}

Acem Ali hakkında bilgiler içeren ve günümüzde yaygın olarak kullanılan kaynakların bir kısmı, metinde daha kolay takip edilebilmesi amacıyla, aşağıda tablo halinde verilmiştir (Tablo 1).

Tablo 1. Acem Ali ile İlgili Kaynaklar

\begin{tabular}{|c|c|c|}
\hline Hakkında & İfade/İddia/ Görüş & Kaynak \\
\hline \multirow{12}{*}{ Ad1/Ünvanı } & $\begin{array}{l}\text { Acem lakabı verilen Esir Ali } \\
\text { Vakfiyesinde asıl şöhreti Esir Ali }\end{array}$ & $\begin{array}{l}\text { (Altan, 1937, s. 81) } \\
\text { (Kumbarac1lar, 1937, s. 59) }\end{array}$ \\
\hline & Mimarbaşı Acem Ali & (Kumbarac1lar, 1937, s. 59) \\
\hline & Esir Ali (Acem Ali) & (Hersek, 1990, s. 43) \\
\hline & Acem Alisi & $\begin{array}{l}\text { (Sâî Mustafa Çelebi, 1315, s. 26); } \\
\text { (Yerasimos, 2005, s. 41) }\end{array}$ \\
\hline & Alaüddin Ali bin Abdullah & (Yerasimos, 2005, s. 41) \\
\hline & Alaüddin Ali Bey ibni Abdülkerim re’isü'l-mimârinül-emîrîn & $\begin{array}{l}\text { Acem Ali'nin Eylül } 1525 \text { tarihli } 1 . \\
\text { Vakfiyesi: (Kunter, } 1960 \text {, s. } 438 \text { ); } \\
\text { (Yerasimos, 2005, s. 41) }\end{array}$ \\
\hline & Ali Bey ibni Abdülvehhab & Acem Ali'nin 20 Mart 1537 tarihli \\
\hline & & $\begin{array}{l}\text { 2. Vakfiyesi:(Kunter, 1960, s. 441); } \\
\text { (Yerasimos, 2005, s. 41) }\end{array}$ \\
\hline & Alaeddin & (Orgun, 1938, s. 333) \\
\hline & Mimar Acem Îsâ & (Ertuğrul, 1993, s. 189) \\
\hline & Mimar Ali Tebrizî & $\begin{array}{l}\text { (Dedeyev, Necefli, ve Uslu, 2014, } \\
\text { s. 331) }\end{array}$ \\
\hline & Ali bin Abdullah & (Meriç, 1957, s. 30) \\
\hline \multirow{5}{*}{ Milliyeti } & "Azeri Türklerinden.." & $\begin{array}{l}\text { (Altan, 1937, s.81); (Afetinan, } \\
\text { 1968, s. 27); (Ertuğrul, 1988, s. } \\
\text { 322) }\end{array}$ \\
\hline & Tebrizli & (Dedeyev vd., 2014) \\
\hline & İranlı bir mimar & (Kuban, 1994, s. 62) \\
\hline & Vakfiyedeki baba adlarına bakılırsa (Abdülkerim & (Yerasimos, 2005, s. 38) \\
\hline & Abdülvehhab) Gayrimmüslim bir mimar & \\
\hline \multirow{8}{*}{$\begin{array}{l}\text { Acem } \\
\text { Mimar/Mimarbaşı } \\
\text { Olduğu } \\
\text { Tarih Dönem, } \\
\text { Aralığı }\end{array}$} & Kanuni Sultan Süleyman zamanında mimarbaşı olmuş & (Kumbaracilar, 1937, s. 59) \\
\hline & $\begin{array}{l}\text { Görevi: 16 C } 909 \text { (6 Aralık 1503)- yaz } 1539 \text { ( H.16 C } 909 \text { - } \\
\text { 946); 1511'den sonra baş mimar ünvânı almıştır. }\end{array}$ & (Yerasimos, 2005, s. 39, 41) \\
\hline & $\begin{array}{l}\text { I.Selim döneminde ve Kanuni Süleyman dönemi başlarında } \\
\text { hassa başmimarlığ1 görevi üstlenmiş }\end{array}$ & (Tanman, 1994, s. 465) \\
\hline & Amasya'da 8 çeşme yaptıktan sonra Sultan Selim (Sal.1512- & (Dedeyev vd., 2014, s. 334) \\
\hline & 1520) onu başmimar olarak atadi. & \\
\hline & $\begin{array}{l}\text { Sarayda mimar olarak yetiştirilen Esir Ali (Acem Ali) hassa } \\
\text { başmimarlığına kadar yükselmiş (1534). }\end{array}$ & (Hersek, 1990, s. 43) \\
\hline & $\begin{array}{l}\text { Mimar olarak ilk kez Bayezid Cami inşaatında görevli. İlk } \\
\text { in'amı 16 C } 909 \text { (6 Aralık 1503)'te almıştır. Recep 915'ten } \\
\text { (Ekim 1909) sonra mimarbaşı olmuştur. }\end{array}$ & (Meriç, 1957, s. 31) \\
\hline & $\begin{array}{l}\text { Yakubşah'ın ölümü üzerine 1509'da başmimar olarak atanır, } \\
\text { 1537'ye kadar bu görevi sürdürür. }\end{array}$ & (Mülayim, 2013, s. 205) \\
\hline
\end{tabular}


Tablo 2-Devamı

\begin{tabular}{|c|c|c|c|}
\hline Hakkinc & & İfade/İddia/ Görüş & Kaynak \\
\hline \multirow{4}{*}{$\begin{array}{l}\text { İstanbul'a } \\
\text { Şekli }\end{array}$} & \multirow{4}{*}{ Geliş } & $\begin{array}{l}\text { Sinan'ın İran seferinden gelirken getirdiği İranlı bir mimar } \\
\text { Selim'in doğu seferi sırasında İranlılar'dan esir alındı }\end{array}$ & $\begin{array}{l}\text { (Kuban, 1994, s. 62) } \\
\text { (Ertuğrul, 1988, s. 322) }\end{array}$ \\
\hline & & I.Selim döneminde İran'dan esir olarak & (Hersek, 1990, s. 43) \\
\hline & & İran harbinde esir edilip & (Kumbarac1lar, 1937, s. 59) \\
\hline & & Yavuz’un İran zaferi dönüşünde yanında getirdiği & (Altan, 1937, s. 81) \\
\hline \multirow{10}{*}{ Ölüm Tarihi } & & 1537 & $\begin{array}{l}\text { (Tanman, 1994, s. 465); (Mülayim, } \\
\text { Sinan, 2009, s. 225); (Refik, 1977, } \\
\text { s. 33); (Mülayim, 2013, s. 205) }\end{array}$ \\
\hline & & $944 / 1537$ & (Kumbaracilar, 1937, s. 59) \\
\hline & & $944 / 1534$ & (Altan, 1937, s. 83) \\
\hline & & $\begin{array}{l}8 \text { Şevval } 943 \text { ( } 20 \text { Mart 1537) tarihli vakfiyenin tanziminden kısa } \\
\text { bir müddet sonra öldüğü anlaşılmaktadır. }\end{array}$ & (Ertuğrul, 1988, s. 322) \\
\hline & & Lütfü Paşa Sadrazam olunca & (Afetinan, 1968, s. 27) \\
\hline & & 1538 & (Kuran, 1987, s. 23, 26) \\
\hline & & 1539 yilının yazında & (Dedeyev vd., 2014, s. 329, 336) \\
\hline & & Yaz 1539 & (Yerasimos, 2005, s. 41) \\
\hline & & $\begin{array}{l}\text { Hikmet-i hüdâ-yı teala Mimar Acem Alisi fevt olub mi'mârlık } \\
\text { mahlûl olur. Ol demlerde Vezîr-i A'zâm Ayas paşa dahî ahirete } \\
\text { rihlet eyler.. }\end{array}$ & (Sâî Mustafa Çelebi, 1315, s. 26) \\
\hline & & $\begin{array}{l}\text { Ayas Paşa'nın vefat tarihi: } 26 \text { Safer 946/13 Temmuz } 1539 \\
\text { (Ayrıca bkz: Tablo 3) [Ayas Paşa'nın vefatı, kaynaklarda } \\
\text { görüleceği üzere Acem Ali ile ilgili olduğu için buraya } \\
\text { alınmıştır.] }\end{array}$ & (Lütfi Paşa, 1341, s. 370) \\
\hline
\end{tabular}

Yukarıdaki tablodan anlaşılacağı üzere mevcut bazı yayınlarda, Mimar Sinan'dan önceki mimarbaşı olan Acem Ali'nin milliyeti, nereden geldiği/getirildiği ve vefat tarihi hakkında farklı yaklaşımlar sergilenmektedir. Mevcut yayınlara bakıldığında, bazılarında Acem Ali’nin vefat tarihi 1537 ya da 1538 olarak verilmişken bazılarında 1539 tarihi -ki doğrusu budur- verilmektedir. Aynı biçimde Sinan'ın mimarbaşı olduğu tarih konusunda da 1537 ile 1539 tarihleri arasında gidip gelinmektedir. Acem Ali'nin milliyeti ve geldiği/getirildiği bölge olarak, bir kaynaktaki “..Sinan'ın İran seferinden gelirken getirdiği Iranl bir mimarn Edirne'deki bir camiyi örnek alarak cami yapmıs olmast ikna edici bir sav değildir." ifadeleriyle Acem Ali'nin Sinan tarafından İran'dan getirilen İranlı bir mimar olduğu öne sürülmüştür (Kuban, 1994, s. 62). Aynı bilgi yakın tarihlerdeki bir yayında da tekrarlanır (Nemlioğlu, 2015, s. 31-35). Aynı müellife ait iki kaynakta Acem Ali'nin, Esir Ali lakabından hareketle Yavuz'un Doğu seferi sırasında İranlılardan esir alındığı yazar ve ölüm tarihi olarak da 944/1537 gösterilir (Ertuğrul, 1988, s. 322); (Ertuğrul, 1993, s. 189). Müellifin burada verdiği bilgilerin, hem Lütfi Paşa'nın verdiği bilgilere hem de Sinan'ın ifadelerine aykırı olduğu görülmektedir.

Yine Acem Ali ile ilgili hemen her akademik yayında başvuru kaynağı olarak gösterilen bir başka eserde "Mimarbass Acem Ali Yavuz. Sultan Selim zamannda yapulan İan harbinde esir edilmis ve İstanbul'a getirildikten sonra mimar olduğu için hassa mimar ve Kanunî Sultan Süleyman zamanında Mimarbaşı olmuştur." denilmiştir. Müellife göre Acem Ali esir olarak ele geçirilen bir mimardır, hem Acem Ali’nin ölüm tarihi hem de Sinan'1n mimarbaşı olduğu tarih 944/1537'dir (Kumbaracılar, 1937, s. 59,60). Aynı süreli yayından bir başka başvuru kaynağı olan yazıda da, Acem Ali’nin İran zaferi dönüşü esir olarak getirilen Azeri Türklerinden olduğu, kendisine Acem lakabı verildiği ve daha sonra mimarbaşı olduğu yazar (Altan, 1937, s. 81). Acem Ali ile ilgili yayınlarda kaynak olarak gösterilen bir başka eserde yine, ".Yavuz Sultan Selim döneminde Iran'dan esir olarak getirilip sarayda mimar olarak yetistirilen Esir Ali (Acem Ali) Hassa Basmimarliğma kadar yükeselmişstir (1534).." denilerek Acem Ali'nin İran'dan esir getirilmiş olduğu iddiası ve 1534 tarihi dile getirilmektedir (Hersek, 1990, s. 43). Başka iki kaynakta Acem Ali'nin ölüm tarihi 1537 olarak gösterilirken (Tanman, 1994, s. 465); (Mülayim, 2009, s. 225), yine yakın tarihli bir başka eserde Mimar Sinan'ın mimarbaş1 olduğu tarih olarak 1538 gösterilmektedir (Mülayim, 2013, s. 207). Ancak aşağıda görüleceği üzere Sinan o tarihlerde henüz Boğdan seferindedir. Mimar Sinan, tezkiresindeki kendi ifadesinde sefer dönüşü, mimarbaşı Acem Alisi ve Vezir Ayas Paşa'nın ölümü üzere yeni Vezir Lütfi Paşa'nın teklifiyle mimarbaşı olarak atandığını belirtmiştir.

Buraya kadar verilen bilgilere göre, Acem Ali’nin İran'dan esir olarak getirilen Azeri Türkü olduğu iddiasını içeren en erken tarihli yayınlar, Mimar Acem Ali ile ilgili sonraki pek çok mimarlık tarihi çalışmasının çelişkili kurgularla oluşturulmasına kaynaklık etmiş, Orgun, Meriç, Kunter ve Yerasimos’un ortaya koydukları sonuçlar ise göz ardı edilmiştir. 
Çok yakın bir tarihte yapılmış başka bir akademik yayın ise ağıllıklı olarak tezini, Acem Ali’nin Tebriz'den getirilen İranlılar arasında olduğu, Acem Ali'nin, isminden hareketle bir takım coğrafi kaynaklara atfen Azeri Türkü olduğu ve Sultan Selim tarafindan 1519'da mimarbaşıllk görevi verildiği iddiası üzerine kurmaktadır (Dedeyev vd., 2014, s. 329-340). Bu yayındaki iddiaların (Acem Ali'nin Tebriz'den getirilen mimar olması iddiası) temel dayanağı, Hüseyin Arslan'in 2001 yllında Kaknüs yayınlarından çıkan kitabıdır (Arslan, 2001). Arslan, adı geçen müelliflerin iddialarına temel teşkil edecek bir bilgiyi eserinde vermiyor olsa da, Dedeyev ve arkadaşlar1 "..Safevi devletinde 'üstatlarnn nažrn' olan Acem Ali de, bu kafilenin içinde 12 Nisan 1515 ynlinda Amasya'dan İstanbul'a gönderilmiş..." olduğu iddiasını savunmuştur (Dedeyev vd., 2014, s. 329, 332). Ancak Hüseyin Arslan'ın kaynak gösterilen kitabının, müelliflerce atıf yapılan ilgili bölümünde Acem Ali ismi hiç geçmemektedir. Kendi kitabında Arslan'ın ifadesi şudur: "..7-27 Safer sene 921/23 Mart-12 Nisan 1515'de yaz̨lmis BOA'da ${ }^{2}$ bulunan Farşa bir defter, Tebriz'den İstanbul'a sürülenlerin mesleklerini, demografike durumlarm ve kimin gözetiminde gönderildiklerine ilişkin açılamalar içermektedir."(Arslan, 2001, s. 325). Görüldügü üzere burada Hüseyin Arslan, aslında defterin 23 Mart-12 Nisan 1515'de yazıldığını belirtmiştir. Dolayısıyla 12 Nisan 1515 tarihi, bu makalede müelliflerce iddia edilen, Acem Ali’nin Tebriz'den önce Amasya'ya, oradan da İstanbul'a gönderilme tarihi değil, Osmanlı arşivinde olduğu belirtilen Farsça yazma defterin istinsah tarihidir. Dedeyev ve arkadaşlarını yanıltan nokta da, bu tarihin yanlış anlaşılması ve tablolardaki bilgilerin vakfiye bilgileri ile karşılaştırılmaması olmalıdır.

Arslan bu defterin dökümünü ayrıca bir tablo halinde vererek, Tablo VII'de mesleği tâcir olarak geçen bir isimden bahseder. Bu kişi "Hoca Pir Ali" olup, adı geçen tabloda aile efradının isimleri ile beraber verilmiştir (Arslan, 2001, s. 327). Buradaki isimler Acem Ali'nin vakfiyesindeki eş ve çocuklarına ait isimlerle uyuşmamaktadır (Kunter, 1960). Dolayısıyla bu tabloda verilen “Tâcir Hoca Pir Ali”nin, Sinan'dan önceki mimarbaşı Acem Ali olması mümkün gözükmemektedir. Aynı eserdeki Tablo XV'te ise bir başka "Hoca Pir Ali" adı geçer. Bu isim "Ulufe Alan Sürgünler Cemaati”" başlı̆̆ı altında, 61 sanat erbâbının yazılı olduğu listenin ikinci sırasında "Üstadlar nâžrı" olarak yazılmıştır. Buradaki Hoca Pir Ali'nin, listede geçen Nakkaş, Zer-ger (Altın imalatçısı), Hakkâk, Şim-keş (Gümüş işlemeci), Şemsir-ker (kılıç imalatçısı), gibi el sanatları mensupları oldukları, Hoca Pir Ali'nin de mimar değil üstadlar nâzırı lakabıyla bu sanatkâr ve zanaatkârların üstadı olduğu anlaşılmaktadır. (Arslan, 2001, s. 332) ${ }^{3}$.

Kısaca Arslan'ın kitabında geçen Tablo VII'deki Hoca Pir Ali'nin, Meriç'in arşiv belgelerine göre ortaya koyduğu bilgilerdeki Acem Ali ve Kunter’in açıkladığ1 vakfiye bilgilerindeki aile fertleri dikkate alınarak yapılan karşılaştırma neticesinde ortaya çıkan Acem Ali ile arasında bir ilişki olmadığ1 görülmektedir. Tablo XV'teki Nazırlar Üstadı Hoca Pir Ali'nin ise mimar olup olmadığı belli değildir. Muhtemelen bu iki Hoca Pir Ali'den, Tebriz'den sürgün gelip Osmanlı Sarayında mimarbaşı olan bir Acem Ali karakteri yaratılmıştır. Ayrıca Arslan'ın bu bilgilerin devamında vurguladığı nokta oldukça önemlidir: "Ulufe alan 70 kişinin mesleklerine göz atuldiğgnda, kâtip ve kü̈cük sanat ve zenaat sahipleri olduğu görülmektedir."(Arslan, 2001, s. 333).

Aynı şekilde Dedeyev ve arkadaşları, Acem Ali için "Esir Ali" sıfatına kaynak olarak Kunter'in açıkladığ1 ikinci vakfiyeyi göstermişlerdir (Dedeyev vd., 2014, s. 333). Ancak Kunter'in söz konusu çalışmasında Esir Ali adı, vakfiyelerinin hiçbirinde geçmemektedir. Adı geçen müellifler için burada da muhtemelen kaynak göstermede sehven bir karış1klık meydana gelmiştir. Buna karşılık bahsedilen makalede Acem Ali'nin vefatı doğru bir tespitle 1539 yıll yazı olarak verilmiştir (Dedeyev vd., 2014, s. 349).

Yakın tarihli bir başka yayında, müellifin Acem Ali ile ilgili yaygın iki görüşten bahsettiği görülür (Kerimova, 2017). Müellife göre bu görüşlerden ilki, Acem Ali’nin Çaldıran savaşından önce esir getirildiğidir. İkincisi ise 1515 'te önce Amasya'ya sonra da İstanbul'a getirildiği görüşüdür (Kerimova, 2017, s. 2081-82). Müellifin bu görüşlerden ikincisini kabul ettiği ve araştırmasını bunun üzerine kurduğu anlaşıllyor ${ }^{4}$. Ayrıca müellif, Acem Ali'nin Üstadlar Nazırı olduğu iddiasına da, Hüseyin Arslan'ın kitabındaki verilerle kıyaslamaksızın, Dedeyev ve arkadaşlarının çalışmasına atıfla, Osmanlı mimarisinde Acem Ali'nin klasik Osmanlı mimarisi ile Tebriz üslubunu birleştiren mimar olduğunu iddia etmiştir (Kerimova, 2017, s. 2082).

\footnotetext{
2 Yeni adı: Cumhurbaşkanlığı Osmanlı Arşivi (COA).

3 İlgili bölüm Arslan'n kitabında Nâzır-1 Üstâdân olarak Tablo XV'te ikinci sırada geçmektedir.

4 Araştırmasının kopyasını gönderen müellife teşekkür ederim.
} 


\section{Vakfiye ve İlk Kaynaklara Göre Hassa Mimarbaşı Acem Ali}

Mimarbaşı Acem Ali, vakfiyelerindeki tarihler dikkate Mart 1537'de hayattadır (Kunter, 1960); (Yüksel, 2004, s. 9), (Tablo 2). Acem Ali’nin her iki vakfiyesinde de baba adı olarak iki farklı isim kullanması, Sinan'da olduğu gibi, onun da mühtedi bir mimar, yani gayrimüslim kökenli olduğunu göstermektedir (Yerasimos, 2005, s. 38). Vakfiye verilerine göre mühendisler üstadı ve mimarlar reisi olan Acem Ali'nin aile fertleri şunlardır: Eşi; Hilal kızı Fatma, Kızları; Şemî Hatun, Sitti Hatun ve kendisi hayattayken vefat eden Fatma hanım, Oğulları; Hamza ve Hasan Çelebi (Kunter, 1960, s. 440, 441, 442).

Tablo 3. Vakfiye ve İlk Kaynaklara Göre Acem Alinin Künyesi

\begin{tabular}{|c|c|}
\hline Acem Ali'nin Ísmi ve Şöhreti & Kaynak \\
\hline $\begin{array}{l}\text { "..El-üstâdü'-l kâmili'l-babîr ve'l-mühendisü'l-mâbirü'l-hatîr. } \\
\text { Ali Bey ibni Abdülkerim reisül-mi'mârini'l-emîrîn” }\end{array}$ & $\begin{array}{l}\text { Acem Ali'nin Eylül } 1525 \text { tarihli 1. Vakfiyesi: (Kunter, 1960, s } \\
\text { 438) }\end{array}$ \\
\hline $\begin{array}{l}\text { “..El-üstâdü'-l kâmili'l-babîr ve'l-mühendisü'l-mâbirü'l-batîr } \\
\text { mühendisîn reisül-mi'mârîn..Ali Bey ibni Abdülvehhab” }\end{array}$ & $\begin{array}{l}\text { Acem Ali'nin } 20 \text { Mart } 1537 \text { tarihli 2. Vakfiyesi: (Kunter, 1960, } \\
\text { s. 441) }\end{array}$ \\
\hline "..Mimar Acem Alisi..." & Mimar Sinan'ın kendi ifadesi (Sâi Mustafa Çelebi, 1315, s. 26) \\
\hline ".Acem lakabı verilen Esir Ali Başmimar olduktan sonra.." & (Altan, 1937, s. 81) \\
\hline $\begin{array}{l}\text { "Kitaplarda nam Acem Ali yazllmakta ise de vakfiyesinde } \\
\text { Esir Alidir." }\end{array}$ & $\begin{array}{l}\text { Vakfiyelerinde böyle bir bilgi olmamasına rağmen İzzet } \\
\text { Kumbaracılar bu nitelemeyi yapmıştır (Kumbaracilar, 1937, s. } \\
\text { 59) }\end{array}$ \\
\hline
\end{tabular}

M. Zarif Orgun, ehl-i hiref defterleri üzerine yaptığı çalışmada o tarihlerde Topkapı Sarayı arşivinde bulunan 9706 ve 10141 numaralı iki defteri incelemiştir. Orgun üzerinde tarih bilgisi bulunmayan 9706 nolu defterde geçen hassa mimarları arasında "Mimarbaşı Alâaddin" olarak nitelenen mimarın, Acem Ali olduğunu belirtmiştir. Defterlere düşülen notlara bakarak Orgun söz konusu ehl-i hiref defterlerini 932'den (1525-26'dan) önceye tarihlemiş, Acem Ali'nin I. Selim dönemine tarihlenen bir arîzasına da yer vermiştir (Orgun, 1938, s. 333, 334).

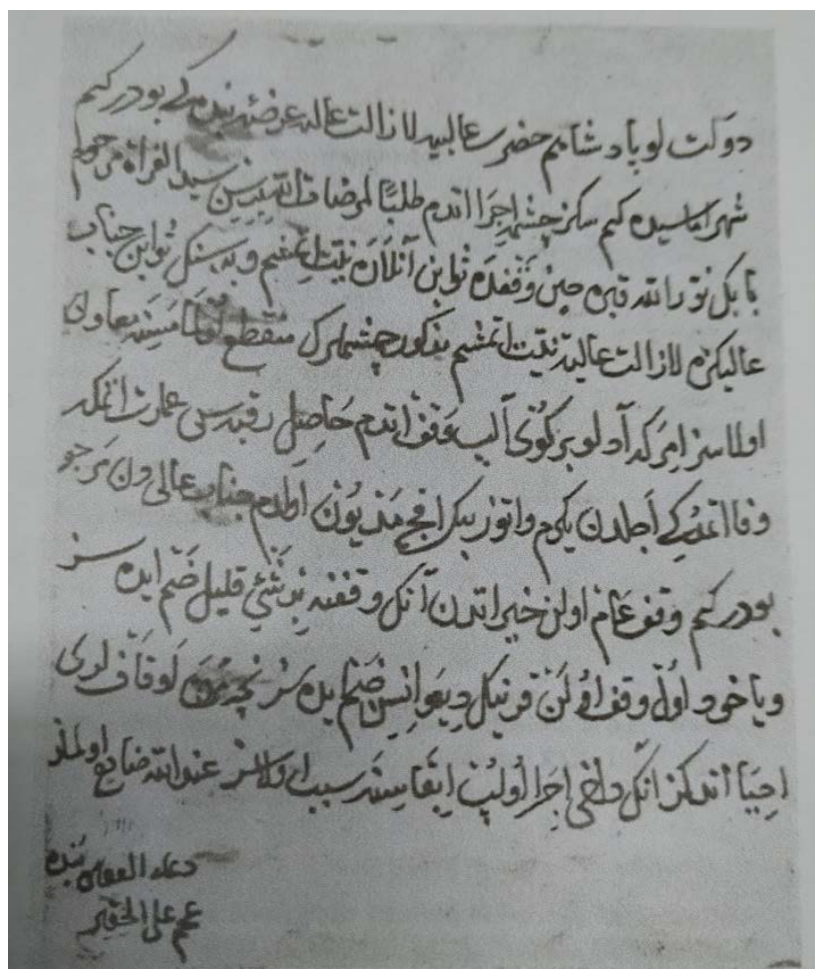

Resim 1. Acem Ali İmzasyyla I. Selim'e Sunulan Bir Arîza 
Aynı şekilde Yerasimos da, oğlu Hamza'nın 1525-26 tarihli hassa mimarları listesinde yer almaması nedeniyle 10137 nolu defteri 1524'ten önceye tarihlendirir (Yerasimos, 2005, s. 38, 39, 41, 56). Baz1 araştırmacıların, Orgun'un yayınladığı listelerde geçen "Mimarbaşı Alâaddin" yani Acem Ali’nin, Rıfkı Melül Meriç’te "Ali bin Abdullah" adıyla geçmesinden hareketle, çağdaşı ve aynı zamanda Acem Ali'nin ikinci vakfiyesindeki şahidi olarak geçen mimar ile karıştırdığ görülmektedir. Burada yapılan değerlendirmelere bakıllıssa, vakfiyeler ve Acem Ali’nin I. Selim dönemine tarihlenen arizasındaki (Resim 1) ${ }^{5}$ Acem Ali ifadesi dikkate alınmadan çıkarım yapılmaya çalışılması, şahitlik yapan "Alaeddin bin Abdullah" ile Acem Ali'nin karıştırılmasına sebep olmuştur (Dündar, 2002, s. 233, 236).

Acem Ali ile ilgili arşiv belgelerinden Rifk1 Melül Meriç'in çıkardığı sonuca ve Yerasimos'un denemesine göre Acem Ali'nin mimar ve mimarbaşllık tarihçesi şöyledir (Meriç, 1957, s. 30, 31); (Yerasimos, 2005, s. 38, 39, 41, 56), (Tablo 3):

\section{Tablo 3. Acem Ali'nin Mimar Ve Mimarbaşıllk Taribçesi}

\begin{tabular}{|c|c|}
\hline Görev/Faaliyet/Ödüllendirme & Tarih/Tarih Aralığ1 \\
\hline $\begin{array}{l}\text { Beyazid Camii inşaatı sırasında Mimar Yakub Şah bin Sultan Şah'ın halifesi olarak hilât } \\
\text { giymiştir. }\end{array}$ & $\begin{array}{l}6 \text { Aralık 1503, } 1 \text { Haziran 1504, } \\
3 \text { Ekim 1504, } 3 \text { Eylül } 1505 \\
\text { tarihlerinde }\end{array}$ \\
\hline $\begin{array}{l}\text { Pirinç Hanı'nın yapımında görevlendirilerek Bursa'ya gider. Aynı yıl } 19 \text { Aralık'ta, Han'ın } \\
\text { yapımındaki hizmetinden dolayı hilat giydirilir. }\end{array}$ & Mayıs-Haziran 1507 \\
\hline Belirtilmeyen bir hizmetten dolayı in'am alır. & 9 Ocak 1509 \\
\hline $\begin{array}{l}\text { Amasya'daki II. Bayezid Camii tamiri dolayısıyla hilat giydirilir ve ayrıca } 2000 \text { akçe bağış } \\
\text { yapılır. }\end{array}$ & 11 Nisan 1509 \\
\hline Boğazkesen Kalesi’nde yapmış olduğu hamamdan dolayı hilat ve 2000 akçe hediye edilir. & 5 Mart 1510 \\
\hline $\begin{array}{l}\text { Depremden (10 Eylül 1509) sonra hasar gören İstanbul surlarının tamiri neticesinde } 3000 \\
\text { akçe ve câme çatma alır }{ }^{6}\end{array}$ & 26 May1s 1510 \\
\hline $\begin{array}{l}\text { II.Bâyezid'in depremden sonra taşındığı Dimetoka Sarayı tamirinden dolayı } 3000 \text { akçe ve } \\
\text { câme çatma alır. }\end{array}$ & 17 Ağustos 1510 \\
\hline $\begin{array}{l}\text { II. Bayezid döneminde oğlu mimar Hamza da dahil olmak üzere diğer mimarlar ve } \\
\text { suyolcuları ile birlikte ödüllendirilir. }\end{array}$ & 7 Eylül 1511 \\
\hline $\begin{array}{l}\text { Vakfiye kayıtlarından çok önceye tarihlenen bir in'am kaydında, Hamza adında bir oğlu } \\
\text { olduğu bilgisi geçmektedir. }\end{array}$ & 8 Ağustos 1511 tarihli \\
\hline Fatih Cami tamiratı sonunda 5000 akçe alır. & 23 Kasim 1511 \\
\hline $\begin{array}{l}\text { I. Selim, öldürülen kardeşlerinin türbelerinin yapımı için "Mimar Alaüddin’ı görevlendirir. } \\
\text { "Acem Ali” imzasıyla I. Selim'e sunduğu bir arizasında Amasya'da } 8 \text { çeşme yaptığını ve kısaca } \\
\text { bu hayrata Padişahtan yardım etmesini, katkıda bulunmasını ister7. }\end{array}$ & 19 Mayıs 1513 \\
\hline Hassa Mimarı olan oğlu Hamza ile birlikte Topkapı Sarayı sularını tanzim ve taksim eder. & 1526’dan önce \\
\hline $\begin{array}{l}\text { 1525-26 tarihli Cemaat-i Mi'marân listesinin başında "Alaüddin"» adıyla } 45 \text { akçe yevmiye ile } \\
\text { mimarbaşıdır. }\end{array}$ & $1525-26$ \\
\hline $\begin{array}{l}\text { Oldukça zengin olduğu görülen ilk vakfiyesinde "Alaüddin Ali Bey ibni Abdülkerim” ismiyle } \\
\text { reisü'l-mi'mârin olduğu elkâbından anlaşılmaktadır. }\end{array}$ & $\begin{array}{l}\text { Evâil-i zilhicce 931/ Eylül } \\
1525 \text { (vakfiye tarihi) }\end{array}$ \\
\hline Topkapı Sarayı Divânhânesi yapımı bitiminde hilat giydirilir. & 1528 \\
\hline $\begin{array}{l}\text { İkinci vakfiyesinde "Ali Bey ibni Abdülvehhab" olarak "Acem Alisi" mahallesinde kurmuş } \\
\text { olduğu cami, mektep ve zaviye giderleri için mal varlığını vakfeder. }\end{array}$ & $\begin{array}{l}8 \text { Şevval 943/20 Mart } 1537 \\
\text { (vakfiye tarihi) }\end{array}$ \\
\hline Veba'dan vefat eden Ayas Paşa ile aynı günlerde [Sinan'ın her ikisi için çok yakın tarihlerde & 1539 Temmuz \\
\hline
\end{tabular}

\footnotetext{
5 Arîza görseli şuradan alınmıştır: (Orgun, 1938, s. 334)

629 Mart-1 Haziran 1510 tarihleri arasında depremden hasar gören yerler elden geçirilmiştir. Bkz.: (Mülayim, 2013, s. 205)

7 Amasya'daki çeşmeler ile ilgili belgenin Türkçesi için bkz.: (Nemlioğlu, 2015, s. 32)

8 M. Zarif ORGUN da 1525-26 tarihli Cemaat-1 Mimarân listelerinde görülen Alaaddin'in, Acem Ali adı ile bilinen meşhur mimar olduğunu belirtir (Orgun, 1938, s. 333-334)
} 
Acem Ali'ye ait vakfiyeler ile hakkında dökümü yapılan arșiv belgeleri haricinde, Sinan'ın biyografileri ile Lütfi Paşa'nın kitabı da Acem Ali hakkında ciddi ve güvenilir veri sağlayan temel kaynaklardır. Hayati Develinin büyük olasılıkla Sinan tarafindan bizzat kaleme alındığını söylediği (Develi ve Rıfat, 2003, s.1314)9 Tuhfetül Mimarin, Adsız Risale ve Risaletül Mimariye'nin dişındaki eseri olan Tezkiret'ü-l Bünyân'da

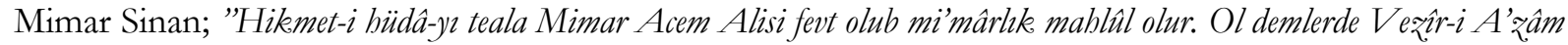
Ayas paşa dabî abirete riblet eyler.."demektedir (Sâi Mustafa Çelebi, 1315, s.26) ${ }^{10}$. Sinan, Tezkiret'ü-1 Ebniyye $^{11}$, Tuhfet'ü-l Mi'mârîn ${ }^{12}$, Risalet'ü-l Mi'mâriye ${ }^{13}$ ve Adsız Risale'de ${ }^{14}$ "..Karaboğdan seferine gittim. Bu seferden dönüsü̈mde mimarbaşı oldum..” demektedir. Karaboğdan seferi 9 Temmuz 1538'de, Kanuni’nin ordusuyla İstanbul'dan hareketiyle başlamış ve 16 Eylül 1538'de Kanuni, Boğdan'ın başkenti Suçav kalesine gelmiştir. Ekim 1538'de ise Edirne'ye ulaşmıştır (Erdoğru, 2014, s. 517, 418, 519). Kanuni, 13 Nisan 1539'da İstanbul'a gelmişti (Anonim, 1992, s.147). Dolayısıyla 1538 sonlarına doğru Karaboğdan seferi neticelenmiş ve 1539 yllı bahar aylarında İstanbul'a dönülmüsstür. Sinan'ın Tezkiret'ül Bünyân'daki ifadelerinden anlaşılacağı üzere Mimar Acem Ali ve Ayas Paşa çok yakın tarihlerde "ol demlerde" ölmüştür. Nitekim Ayas Paşa'nın halefi Lütfi Paşa, Tevârih-i Al-i Osman adlı kitabında 946 senesi Safer ayının (Temmuz 1539) vakalarını anlatırken Ayas Paşa'nın vefat sebebi ile birlikte vefat tarihini günü gününe verir: "ve Târib-i mezkûrda İslambol'da ziyâde ta'ûn olup, mâh-ı mezkûrun (Safer Ayz) yirmi altısinda Ayas Paşa mat'ûn olup vefat etdi. Ve âmn yerine bu fakîr vęîr-i a'ram old."'(Lütfi Paşa, 1341, s.370) ve (Resim 2) ${ }^{15}$.

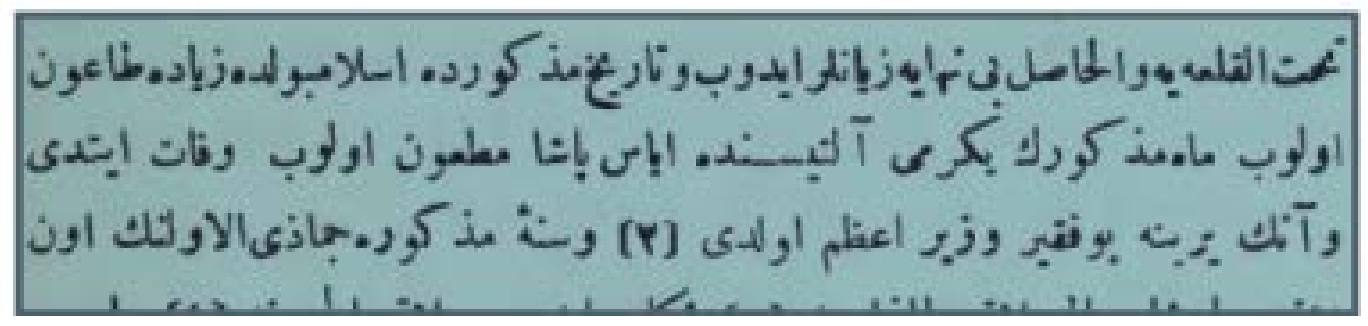

Resim 2. Lütfi Paşa'nnn Tevâribi’nde Geçen Ayas Pașa'nnn Vefat ve Kendisinin Vez̧ir Olduğu Tarih

Lütfi Paşa’nın aktardıklarına göre o sıralarda İstanbul'da veba salgını olmuş, bu salgında Ayas Paşa 26 Safer 946/13 Temmuz 1539'da vebaya yakalanarak vefat etmiştir. Bunun üzerine Ayas Paşa’nın yerine kendisinin veziriazam olduğunu ifade etmektedir ki, Ayas Paşa'nın mezar taşındaki "946 ynl Safer ayı sonları" kaydı da bunu doğrulamaktadır (Resim 3). Ancak, Acem Ali'de olduğu gibi Ayas Paşa'nın vefat tarihi konusunda farklı bilgiler verilmektedir. Lütfi Paşa'nın eserindeki bilgilerin aksine Hüseyin Ayvansarâyî̀nin iki eserinde Ayas Paşa'nın vefat tarihi “944/1537-38” olarak geçer (Ayvansarâyî Hâfız Hüseyin, 1978, s.78); (Ayvansarâyi Hüseyin Efendi, Ali Satı Efendi ve Süleyman Besim Efendi, 2001, s.254, 342). Ahmet Refik ise Ayas Paşa’nın vefat tarihi olarak 1535'i gösterir (Refik, 1931, s.19). Bu ve benzeri eserler, daha sonra yazılmış olan pek çok metnin kaynağı olduğu için bu eserlerdeki tarih farklılıkları, şimdi görülen ihtilafların da temelini oluşturmuştur denilebilir.

\footnotetext{
${ }^{9}$ M. Zeki Sönmez aynı șeyi Risatlet'ül Mimariye ve Adsız Risale için söyler: (Sönmez, 2014, s. 22, 23)

${ }^{10}$ Sinan'ın biyografileriyle ilgili karşılaştırmalı metinleri içeren önemli bir yayın için bkz: (Necipoğlu, Crane ve Akın, 2006)

${ }^{11}$ Bkz.: (Sâî Mustafa Celebi, 1315, s. 64)

${ }^{12}$ Bkz.: (Sâî Mustafa Çelebi, 1315, s. 80)

${ }^{13}$ Bkz.: (Sâî Mustafa Çelebi, 1315, s. 97)

${ }^{14}$ Bkz.: (Sâî Mustafa Çelebi, 1315, s. 98)

15 Ayas Paşa'nın vefat tarihi için: (Eyice, 1991, s. 204);(Yerasimos, 2005, s. 37); (Develi \& Rifat, 2003, s. 42)
} 


\section{BİLMIŞ}

Kısacası, Ayas Paşa'nın yerine Vezir-i Azam olarak atanan Lütfi Paşa'nın tavsiyesiyle Sinan'ın hasekilikten mimarbaşılığa getirilişi 1539 tarihinde, muhtemelen de Temmuz ayı sonlarında olmuştur. Bu konuda Gülru Necipoğlu, Semavi Eyice, Oktay Aslanapa ve Afet İnan da, Hassa Mimarbaşı Acem Ali'nin yerine Sinan'in tayin tarihi olarak 1539'u vermektedir (Aslanapa, 1992, s.5), (Afetinan, 1968, s.27), (Necipoğlu, Crane \& Akın, 2006, s.6), (Necipoğlu, 2013, s.180), (Eyice, 1991, s.204) ${ }^{16}$. Sinan'ın Hassa mimarbaşı ünvanıyla yaptı̆̆ ilk işlerinden biri olarak da geçen (Eyice, 1991, s. 204) Ayaş Paşa için yapılması gereken türbe nedeniyle Sâi Mustafa Çelebi’nin belirttiğine göre, Eyüp'teki türbesinin yapım işi, Lütfi Paşa'nın tavsiyesiyle artık hassa mimarbaşı olan Mimar Sinan'a verilmiştir (Sâi Mustafa Çelebi, 1315, s.26) ${ }^{17}$. Buraya kadar açık bir şekilde ortaya çıkan sonuca göre; Sinan'dan önce Hassa mimarbaşı olan Acem Ali ve Ayas paşa Temmuz 1539 tarihlerinde vefat etmişlerdir ${ }^{18}$. Mimar Sinan, Lütfi Paşa'nın önerisiyle hem Mimar Acem Ali’nin hem de Ayas Paşa'nın ölümünden sonra 1539 yllı Temmuz sonlarında Hassa mimarbaşı olarak atanmış ve ilk olarak Ayas Paşa’nın Türbesinin yapımı için görevlendirilmiştir.

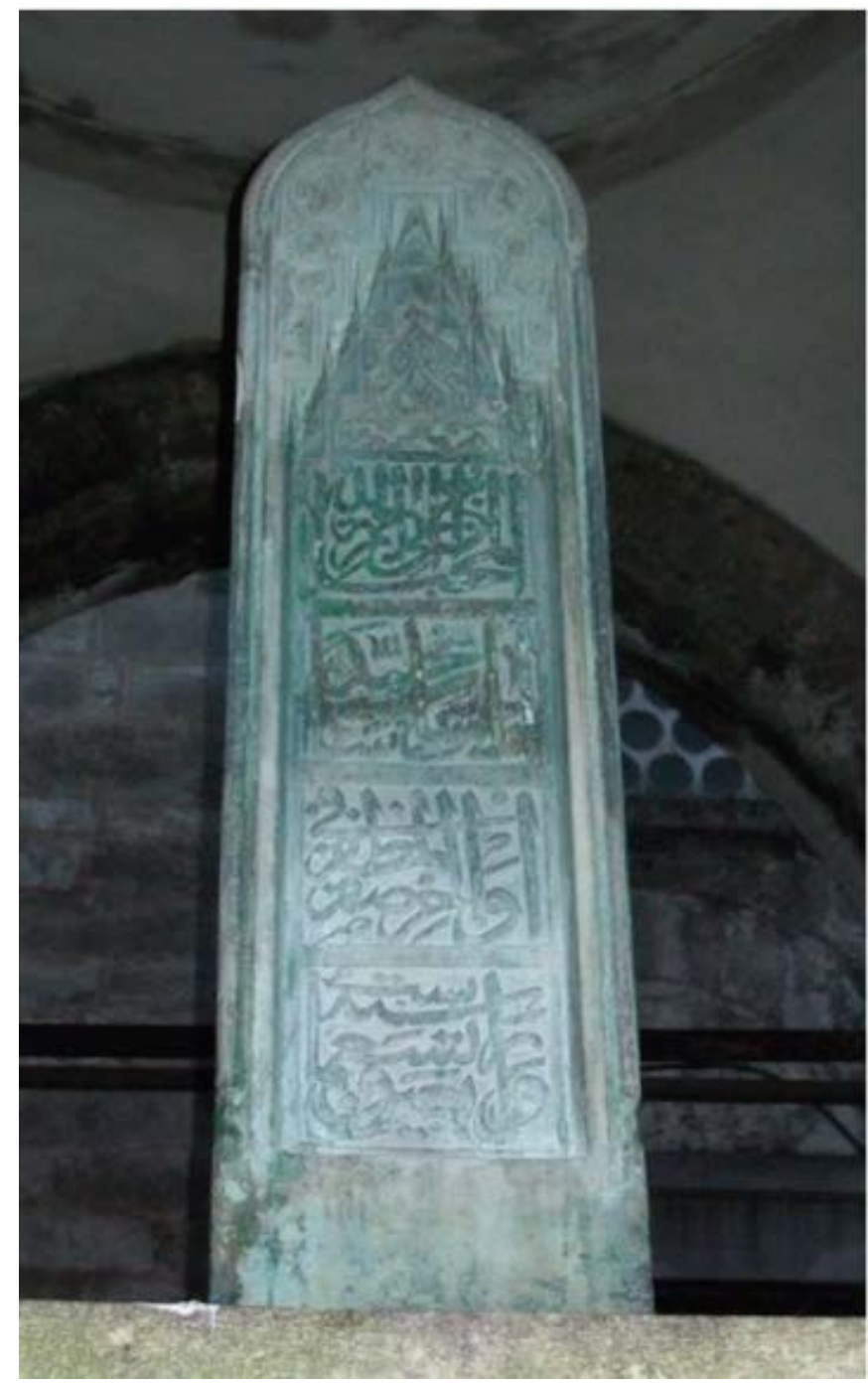

Resim 3. Ayas Paşa'nun Mezar Taşı (Evâhir-i Safer'ülMuzaffer Sitte ve Erba'in ve Tis'amie/946)

\footnotetext{
16 Sinan'ın mimarbaşıllı̆ga atanma tarihi için Aptullah Kuran ise 1538 tarihini vermektedir. Bkz.: (Kuran, 1987, s.23, 26)

${ }_{17}$ Yazma nüshasından Türkçeleştirilmiş başka bir metin için bkz.: (Saatçi, 1989).

18 Acem Ali ile ilgili Hadika'da 'Mi'mar Camii' maddesinde, banisi olduğu caminin mihrabı önünde medfun olduğu yazar, fakat burada ölüm tarihi verilmez, mezar taşında da ölüm tarihi yazmaz. Bkz.: (Ayvansarâyi vd., 2001, s. 272)
} 
Acem Ali ile ilgili daha gerçekçi dayanaklara sahip yorumu ise Stefanos Yerasimos yapıyor olmalıdır:

Ali bin Abdullab'in durumu ise daha karş̧ıtır. Elimizdeki tüm veriler bunun Alaüddin Ali ya da Acem

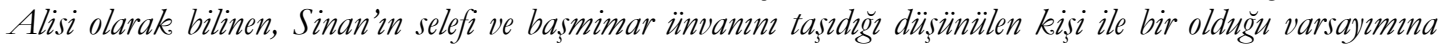
götürïyor, ancak hiçbiri de kesin bir kant getirmiyor. Bununla birlikte iki seyden emin olabiliriz; birincisi iki vakfiyesinin birincisinde ibni Abdülkerim, ikincisinde ibni Abdülvehbab baba adv ile anulan Acem Ali'nin gayrimüslim kökenli olduğudur...ikincisi ise Acem Alinin, bu lakabına rağmen, Yavuz. Selim tarafindan 1514'te Tebriz'den getirilmediğidir. Yavuz döneminde (tariblendirilen) bir arizada Acem Ali olarak imza atan...1514'te Tebriz'den esir alma ya da sürülïp getirilen bir kişinin, 1520'den önce sekiz cesme yapmasi, köy alp vakfetmesi olanaksiz, görünmektedir. Ayrica, $1525^{\prime}$ te, ondan önceki tüm mimarlardan çok daba zengin bir vakfijye ile 30 dïkekân, 11 ev ve basska mülk ve nakit vakfeden Alaüddin Ali'nin arkasinda uzun bir meslek hayatı olmast gerekiyordu. (Yerasimos, 2005, s. 38, 39).

Hem Orgun hem de Meriç'in açıkladığı arşiv verileri üzerinden ortaya konulan bu mantıklı kurgu üzerine şöyle devam eder Yerasimos:

Sarayın en eski taribli (Ocak-Şubat 1526) Cemâ'at-ı Nakkaaşân listesinde ado geg̣en İran kökenli on kişiden üs̆ü Tebriżden sürgün gelmis, biri II. Bayezid zamannda Acem'den gelmis, dördünün babası acem üstadlarndan olup kendileri II. Bayezৃid (2), I. Selim (1), ya da I. Süleyman (1) zamannda nakkaş̧hğa alnmmstır. Ayrnca sürgün gelen üc kişi, önce Amasya'ya getirilmis sonra da İstanbul Hassa barcuna havâle olunmustur. Buradan iki sonuc çıarabiliyorus, İran'dan gelen sanaţ̧lar II. Bayezid zamannda gelmeye başlamış ve Amasya bu gelişin önemli bir uğrağı olmustur. Bu durumda 'Acem' Alinin 1514 Tebriz Fethi ve oradan yapılan sanatkâr sürgünü ile bağlantsimnn gerekçesi kalmaz (Yerasimos, 2005, s. 39).

[nitekim yukarıda belirtildiği üzere sürgün gelen sanatkârların tablosunda geçen kişilerin Acem Ali olamayacağı aşikârdır] ${ }^{19}$. Yerasimos devamla şöyle diyerek Acem Ali ile ilgili mütalaasını sunar;

II. Bayezid zamannda Amasya yolu ile gelmis ya da getirilmis biri olmall. Amasya bağlantıst ise Yakub Şab'la Alaüddin Ali bin Abdullab'ı birbirlerine bağladiğ gibi baskea varsaymlara da götürür. II. Bayezid tabta geçmeden önce Amasya Valisi idi ve saltanatmon ilk mimari yapıtlarm 1481 ile 1486 yallar arasinda Amasya ve Tokat'ta yaptormustır. Burada çalsmms olan yerel mimar ekibinin sonradan İstanbul'a da gelmiş olduğunu düsïnebiliriz. (Yerasimos, 2005, s.39).

\section{Sonuç}

Kunter'in Acem Ali'ye ait vakfiye dökümlerinden, Stefanos Yerasimos'un denemesinden, M. Zarif Orgun ve R. Melül Meriç'in arşiv belgelerine dayalı çıkarımlarından anlaşılacağı üzere, II. Bayezid'in Amasya valiliği döneminde oranın yerel mimarlarından olduğu sonucu ağırlık kazanan Acem Ali, Yavuz’un Tebriz seferinden çok önce Anadolu'ya gelmiş olmalıdır. Ayrıca Acem Ali birinci vakfiyesinin evâili Zilhicce 931/Eylül başlar 1525 tarihi dikkate alındığında o tarihlerde mimarbaşı olduğu kesindir (Necipoğlu vd., 2006, s.134) ${ }^{20}$. Acem Ali, mimar ve mimarbaşı olarak görev yaptığ1 1503 ile 1539 tarihleri arasında, Osmanlı devletinin neredeyse 250 ylllık mimari geleneğinin/birikiminin Sinan'dan önceki son halkası olan mimarbaşıdır.

Acem Ali, isminin en erken geçtiği 1503 tarihinde, Beyazid Camii inşaatı sırasında Mimar Yakub Şah bin Sultan Şah'ın halifesi olarak hilât giymiş bir mimardır. 1507'de Pirinç Hanı'nın yapımında görevlendirilerek Bursa'ya giden Acem Ali, daha sonra II. Bayezid Camii, İstanbul surları, II. Bâyezid'in depremden sonra taşındığı Dimetoka Sarayı, Fatih Cami gibi eserlerin tamirlerinde çalışıştır. 1513’te Padişah I. Selim tarafindan türbe yapımları için görevlendirilir. Daha sonra Acem Ali imzasıyla yine padişah I. Selim'den Amasya'da yaptığı çeşmeler için yardım ister. Hassa Mimarı olan oğlu Hamza ile birlikte Topkapı Sarayı sularını tanzim ve taksim eder. Daha pek çok görevde çalışış olduğu anlaşılan Acem Ali'nin, uzunca bir süre hassa mimarı (30 yıla yakın mimarbaşı olarak geçen bir meslek hayatı) olarak görev yapmış bir mimar olmasından hareketle Sinan'ın mimar olarak yetişmesinde önemli ölçüde katkısı olduğu söylenebilir.

Lütfi Paşa'nın Ayas Paşa ile ilgili verdiği bilgiler ile Sinan'ın Acem Ali ile Ayas Paşa'nın yakın tarihlerde vefatı sonrasında mimarbaşı olduğunu belirtmesi, aynı şekilde hem adına düzenlenmiş olan vakfiyeleri hem de Orgun, Kunter, Meriç ve Yerasimos'un arşiv belgeleri üzerine ortaya koyduğu veriler,

\footnotetext{
${ }^{19}$ Köşeli parantez içindeki ifadeler bu makale yazarına aittir.

20 Bkz: 57.not
} 
bahsedilen karışıklı̆g önemli ölçüde gidermektedir. Bununla birlikte, Acem Ali hakkındaki çelişkili bilgilerin, Ayas Paşa'nın, Acem Ali'nin vefat tarihi ve Sinan'ın mimarbaşı olduğu tarihler konusundaki yanlış bilgiler ile 1930'lu yıllarda yapılan yayınların esas alınması ve aynı zamanda bazı yayınların/kaynakların yanlış okunması/sübjektif değerlendirilmesi sonucu ortaya çıktığı görülmektedir. Bu çalışma içerisinde değerlendirilen ve kaynaklar arasında görülen farklı tarihlendirmelerin neticesi olarak ortaya çıkan bilgi karmaşasının da, burada yapılmaya çalısılan karşılaştırmalı okumalar ile açığa kavuşturulduğu umulmaktadır.

\section{Etik Beyan}

“Acem Ali Kimdir? Osmanlı Dönemi Hassa Baş Mimarı Alaeddin Ali b. Abdullah'nn Kişiliği ve Mesleki Kimliği Üzerine Bir İnceleme" başlıklı çalışmanın yazım sürecinde bilimsel, etik ve alıntı kurallarına uyulmuş; toplanan veriler üzerinde herhangi bir tahrifat yapılmamış ve bu çalışma herhangi başka bir akademik yayın ortamına değerlendirme için gönderilmemiştir.

\section{Kaynakça}

Afetinan, A. (1968). Mimar koca sinan. Ankara: Türkiye Emlak Kredi Bankası Yayınları.

Altan, K. (1937). Klasik türk mimarlarından esir ali. Arkitekt, (6), 81-83.

Anonim. (1992). Anonim tevârih-i âl-i osman. İstanbul: Marmara Üniversitesi Fen-Edebiyat Fakültesi Yayınları.

Arslan, H. (2001). 16. yüzynlda osmanl toplumunda yönetim, nüfus, iskân, göc ve sürgün. İstanbul: Kaknüs Yayınları.

Aslanapa, O. (1992). Mimar sinan. Ankara: Kültür Bakanlığ1 Yayınları.

Ayvansarâyî Hâfız Hüseyin. (1978). Vefeyât-ı selâtîn ve meşâhîr-i ricâl. İçinde F. Ç. Derin (Edt.). İstanbul: İstanbul Üniversitesi Edebiyat Fakültesi Yayınları.

Ayvansarâyi Hüseyin Efendi, Ali Satı Efendi ve Süleyman Besim Efendi. (2001). Hadîkatül’l cevâmi. İçinde A. N. Galitekin (Edt.). İstanbul: İşaret Yayınları.

Dedeyev, B., Necefli, T. ve Uslu, R. (2014). Osmanlı imparatorluğunda baş mimarlı̆̆a kadar yükselen tebrizli mimar ali'nin hayat1 ve eserleri. Turkish Studies, 9(4), 329-340.

Develi, H. ve Rıfat, S. (Ed.). (2003). Sâi mustafa çelebi yapılar kitabı-tękiretü'l-bünyan ve tezkiretü'l-ebniye. İstanbul: Koç Kültür Sanat Yayınları.

Dündar, A. (2002). XVI. yüzyll bazı osmanlı mimarlar1. Ankara Üniversitesi İlabiyat Fakültesi Dergisi, 43(1), 231-262.

Erdoğru, M. A. (2014). Kanuni sultan süleyman'ın 1538 tarihli karaboğdan seferi ruznâmesi. Tarih İncelemeleri Dergisi, $29(2), 515-524$

Ertuğrul, Ö. (1988). Acem ali. Türkiye Diyanet Vakfı İslam Ansiklopedisi. İstanbul: TDV İslâm Araştırmaları Merkezi Yayınları.

Ertuğrul, Ö. (1993). Ali (acem). Dünden Bugüne İstanbul Ansiklopedisi. İstanbul: Kültür Bakanlı̆̆ı\&Tarih Vakfı Yayınları.

Eyice, S. (1991). Ayas paşa türbesi. Türkiye Diyanet Vakff İslam Ansiklopedisi. İstanbul: TDV İslâm Araştırmaları Merkezi Yayinlari.

Hersek, C. M. (1990). Osmanlı imparatorluğunda mimarlar ve yapı esnafi. İslâmi Araştırmalar, 4(1), 42-48.

Kerimova, S. (2017). Creative activity of architect ajam ali in the classical ottoman architecture within the context of turkish cultural heritage-klassik osmanli mimarisinde mimar acem ali’nin yaratiçiliki ortak türk kültürel mirasi bağlaminda. İçinde: M. Eğilmez ve S. Balcı (Edt.), Uluslararası Taşköprü Pompeiopolis Bilim Kültür Sanat Araştırmaları Sempozyumu, (ss.2079-2083). Kastamonu: Kastamonu Üniversitesi-Taşköprü Belediyesi Yayını. Erişim adresi: https://yadi.sk/d/soS-JxsS3RMM6v

Kuban, D. (1994). Sultan selim külliyesi. Dünden Bugüne İstanbul Ansiklopedisi. İstanbul: Kültür Bakanlığı-Tarih Vakfi.

Kumbaracilar, İ. (1937). Türk mimarlar1. Arkitekt, (2), 59-60. Erişim adresi: http://dergi.mo.org.tr/dergiler/2/27/194.pdf

Kunter, H. B. (1960). Mimar ali bey'in bilinmeyen iki vakfiyesi. V.Türk Tarih Kongresi, Ankara, 12-17 Nisan 1956 Kuran, A. (1987). Sinan the grand ol master of ottoman architecture (İstanbul.). Washington: Institute of Turkish Studies. Lütfi Paşa. (1341). Tevârib-i âl-i osman. İstanbul: Matbaa-i Amire.

Meriç, R. M. (1957). Beyazıd camii mimarı. II. sultan bâyezid devri mimarları ile bazı binaları, beyazıd camii ile alakalı hususlar, san'atkarlar ve eserleri. Yillı. Arastırmalar Dergisi, (II.), 5-76.

Mülayim, S. (2009). Sinan. Türkiye Diyanet Vakfi Islam Ansiklopedisi. İstanbul: TDV İslâm Araştırmaları Merkezi.

Mülayim, S. (2013). Sinan bin abdülmennan. İstanbul: İSAM Yayınları.

Necipoğlu, G. (2013). Sinan çağı: Osmanlı imparatorluğu'nda mimari külttür. (Çev.G. Ç. Güven). İstanbul: Bilgi Üniversitesi Yayınları.

Necipoğlu, G., Crane, H. ve Akın, E. (2006). Sinan's autobiographies-five sixteenth century texts. İçinde G. Necipoğlu (Edt). Boston: Brill Leiden.

Nemlioğlu, C. (2015). Mimarbaşı acem ali. Türk mimarisinde į bırakanlar (s. 31-35). İstanbul: Çevre ve Şehircilik Bakanlığ1 Yayınları.

Orgun, M. Z. (1938). Hassa mimarlar1. Arkitekt, (12)96, 333-342.

Refik, A. (1931). Mimar sinan. İstanbul: Kanaat Kütüphanesi Yayınları.

Saatçi, S. (1989). Mimar sinan ve tę̧kiretü'l-bünyan. İçinde M. Sözen (Edt.). İstanbul: Emlak Bankası Yayınları. 
Sâî Mustafa Çelebi. (1315). Tę̧kiretü'l-bünyân. İstanbul: Ahmet Cevdet Matbaası.

Sönmez, Z. (2014). Taribi yazma ve belgelerle mimar sinan. İstanbul: Kap1 Yayınlar1.

Tanman, B. (1994). Mimar acem camii ve tekkesi. Dünden Bugüne İstanbul Ansiklopedisi. İstanbul: Kültür Bakanlığ1Tarih Vakfi Yayınları.

Yerasimos, S. (2005). 15.-16.yüzyıl osmanlı mimarları: bir prosopografya denemesi. İçinde D. Mazlum, G. Cephanecigil ve A. Ağar (Edt.), Afife Batur'a Armağan Mimarllk ve Sanat Taribi Yazıları (ss. 37-62). İstanbul: Literatür Yayınları.

Yüksel, İ. A. (2004). Osmanl mimarisinde kanunu sultan süleyman devri (926-974/1520-1566) (C. 6). İstanbul: İstanbul Fetih Cemiyeti Yayınları.

\section{EXTENDED ABSTRACT}

The two prominent architects, Ajam Ali (Acem Ali) and Mimar Sinan, as well as two politicians, Ayas Pasha and Lütfi Pasha, lived during the period when the Ottoman State turned into an empire. In the literature, information about Ajam Ali, the predecessor of Mimar Sinan as the chief royal architect, is quite different from each other. According to the common view, Ajam Ali is either a captive architect brought from Tabriz or an architect who lived in Amasya during the Bayazid II reign, and later brought to İstanbul. The earliest extant in'âmat registry book belongs to Bayazid II period.

Ajam Ali is cited as the successor of Mimar Yakub Shah bin Sultan Shah during the construction of Bayazid II Mosque in in'âmât registry books where his name appears for the first time on December 6, 1503. Having been assigned for the construction of The Pirinç (Rice) Han, he went to Bursa in 1507. He later worked in the restoration of architectural works such as Bayazid II Mosque, İstanbul City Walls, Dimetoka Palace where Bayazid II moved after the earthquake and Fatih Mosque. He was rewarded in 1511 together with his son Hamza who was also recorded as an architect in his waqfiyas. In 1513, he was assigned by Sultan Selim I for the constructions of several tombs. In one of the petitions signed by Ajam Ali which dates back to Yavuz Sultan Selim period, he asked assistance from Sultan Selim I for the fountains he built up in Amasya. Together with his son Hamza as a Hassa Architect, he undertook the coordination and distribution of waters of Topkap1 Palace.

There are two waqfiyas of Ajam Ali dated 1525 and 1537, which survived till present day and were published by Halim Baki Kunter for the first time. In the former waqfiya, Ajam Ali's name is mentioned as "Alâeddin Ali Bey ibni Abdülkerim", whereas it appears as "Ali Bey ibni Abdülvehbab" in the latter. His son Hamza, who is an architect as well, has also been pointed out in these waqfiyas. Presumably, Ajam Ali became the Chief Architect after the death of Yakub Shah preceding himself towards the end of 1509. According to some of the recent studies conducted about Ajam Ali, it has been claimed that Ajam Ali was first sent to Amasya from Tabriz after the campaign of Selim I against Persia and then to İstanbul from Amasya in 1515. However, upon thorough investigations on the resources shown as evidence to the claims, no clear findings verifying the arguments were found in terms of the relationship between assertions and resources. Research on current studies reveals the fact that the claims have been put forward presuming "Hoca Pir Ali" who was sent to İstanbul from Tabriz as one of the artists and registered "Chief of Masters" in the Ottoman State official records, was Ajam Ali, an architect from Persia. Furthermore, it is concluded that there has been no agreement on the date when Ajam Ali died and Mimar Sinan became the Chief Architect in the sources.

According to the studies about Ajam Ali, 1537 and 1538 are pointed out as the dates of his death. Hence, the date when Mimar Sinan became the architect is taken a few years behind and it seems that some of the architectural works have been attributed to him during this time. On the other hand, the dates when Ayas Pasha died and Lütfi Pasha became the vizier, who were both the contemporaries of Ajam Ali and Mimar Sinan, shed light on this issue. The main resources presenting strong and reliable data on Ajam Ali are the waqfiyas of Ajam Ali published by Halim Baki Kunter and the archive documents of the assignment/reward records investigated by researchers such as Rifk1 Melül Meriç, M.Zarif Orgun, and Stefanos Yerasimos. The History Book by Lütfi Pasha and published biographies of Mimar Sinan must also be added to the previously cited resources. Lütfi Pasha who was known as one of the eminent politicians of the time was a historian as well. In his book about the history of Ottoman State from the foundation till 1553, he states that Ayas Pasha passes away in 1539 and he becomes a vizier in the same year. In Mimar Sinan biographies, it is stated that the dates when Ayas Pasha and Ajam Ali died were very close and that Mimar Sinan became the Chief Architect after he returned from Karaboğdan military 
campaign. Karaboğdan military campaign ended when Kanuni Sultan Suleyman returned to İstanbul in 1539 during the spring months. In the light of this information, it can be concluded that Ajam Ali died in July 1539 after Karaboğdan campaign and Mimar Sinan became the Chief Architect following him. Mimar Sinan reconstructed the Tomb of Ayas Pasha as soon as he became the Chief Architect.

The conflicting information about Ajam Ali's life and professional identity in the literature arises from the inaccurate dates regarding his origins and death date mentioned in the current studies as well as the groundless claims in some publications belonging to the second half of the $19^{\text {th }}$ century. The current study aims to clarify the issue by analyzing several evaluations related to the life of Ajam Ali and his profession as an architect based on the data from his two published waqfiyas and the archive documents introduced by Rifk1 Melül Meriç. Finally, in reference to the aforementioned resources, it has been concluded that Ajam Ali, who became a Muslim later, maintained most his career as Chief Architect under Ottoman service throughout his 36 yearlong architectural professional life between 1503 and 1539. It has also been concluded that the frequently stated assumption in the literature that he was a Persian architect brought from Tabriz, attributed to his nickname "Acem Ali", is not based on reliable evidence and that he arrived at Amasya long before Yavuz's Tabriz campaign is a much stronger presumption. 